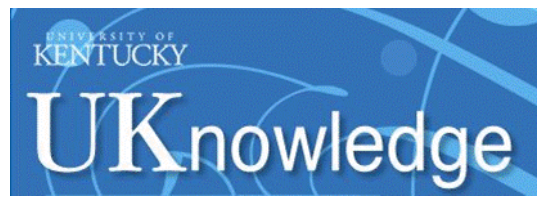

University of Kentucky

UKnowledge

\title{
$5-2019$
}

\section{Inductance Testing for IPM Synchronous Machines According to the New IEEE Std 1812 and Typical Laboratory Practices}

\author{
Vandana Rallabandi \\ University of Kentucky, vandana.rallabandi@uky.edu \\ Narges Taran \\ University of Kentucky, narges.taran@uky.edu \\ Dan M. Ionel \\ University of Kentucky, dan.ionel@uky.edu \\ Ping Zhou \\ ANSYS, Inc.
}

Follow this and additional works at: https://uknowledge.uky.edu/peik_facpub

Part of the Power and Energy Commons

Right click to open a feedback form in a new tab to let us know how this document benefits you.

\section{Repository Citation}

Rallabandi, Vandana; Taran, Narges; Ionel, Dan M.; and Zhou, Ping, "Inductance Testing for IPM Synchronous Machines According to the New IEEE Std 1812 and Typical Laboratory Practices" (2019). Power and Energy Institute of Kentucky Faculty Publications. 23.

https://uknowledge.uky.edu/peik_facpub/23

This Article is brought to you for free and open access by the Power and Energy Institute of Kentucky at UKnowledge. It has been accepted for inclusion in Power and Energy Institute of Kentucky Faculty Publications by an authorized administrator of UKnowledge. For more information, please contact UKnowledge@lsv.uky.edu. 


\title{
Inductance Testing for IPM Synchronous Machines According to the New IEEE Std 1812 and Typical Laboratory Practices
}

\author{
Digital Object Identifier (DOI) \\ https://doi.org/10.1109/TIA.2019.2897668
}

\section{Notes/Citation Information}

Published in IEEE Transactions on Industry Applications, v. 55, issue: 3.

(C) 2019 IEEE Copyright Notice. "Personal use of this material is permitted. Permission from IEEE must be obtained for all other uses, in any current or future media, including reprinting/republishing this material for advertising or promotional purposes, creating new collective works, for resale or redistribution to servers or lists, or reuse of any copyrighted component of this work in other works."

The document available for download is the authors' manuscript version that is accepted for publication. The final published version is copyrighted by IEEE and available as: V. Rallabandi, N. Taran, D. M. Ionel and P. Zhou, "Inductance Testing for IPM Synchronous Machines According to the New IEEE Std 1812 and Typical Laboratory Practices," IEEE Transactions on Industry Applications, Vol. 55, no. 3, pp. 2649-2659, May-June 2019. doi: 10.1109/TIA.2019.2897668 


\section{Inductance Testing for IPM Synchronous Machines According to the New IEEE Std 1812 and Typical Laboratory Practices}

\author{
Vandana Rallabandi, Narges Taran, Dan M. Ionel, FIEEE \\ Department of Electrical and Computer Engineering \\ University of Kentucky, Lexington, KY, USA \\ Emails: vandana.rallabandi@ieee.org, narges.taran@uky.edu,dan.ionel@ieee.org
}

\author{
Ping Zhou, FIEEE \\ ANSYS, Inc. \\ Pittsburgh, PA, USA \\ Email: ping.zhou@ansys.com
}

\begin{abstract}
Equivalent circuit parameters serve as the basis for performance estimation and implementation of power electronic drives controls and therefore their accurate evaluation is very important. Specified in the newly approved IEEE Std 1812, a short-circuit test can be employed, in combination with an opencircuit measurement, in order to determine the back emf and the synchronous inductance. In the case of interior permanent magnet (IPM) machines, this approach can be used only to determine the $d$-axis inductance and additional and separate measurements are required for the $q$-axis inductance. In this respect, various methods, inclusive of dc step response tests, onload tests, and a widely used test in industry, which involves locked-rotor measurements at variable voltage and constant frequency supply, are studied in detail, based on 2D finite element analysis. Locked-rotor methods based on dc current supply and static torque versus rotor position measurements are introduced for determining the $q$-axis inductance in combination with the standardized open-circuit and short-circuit tests. A critical study of the inductances determined from different tests is conducted, and experimental results on an IPM motor design with nonsinusoidal back emf, relatively high torque ripple, and low leakage are presented.
\end{abstract}

Index Terms-Permanent magnet machine, parameter estimation, inductance, d-axis, q-axis, short-circuit test, IEEE Std 1812.

\section{INTRODUCTION}

Equivalent circuit parameters, serving as the basis for performance estimation and control implementations are of the utmost importance for permanent magnet synchronous machines (PMSM). The IEEE Std 1812 discusses the measurement of inductance by performing a short-circuit test [1]. While this allows the determination of $d$-axis inductance, a method to find out the $q$-axis inductance is not included in the standard.

The IEEE Std 115-1983 covers ac standstill tests for the determination of the $d-$ and $q-$ axes inductances of wound rotor synchronous machines [2]. Similar approaches for the inductance testing of PMSM and interior PM (IPM) synchronous motors are commonly used in the industry and discussed in, for example, [3]-[10]. This method involves the application of constant frequency single or three phase ac voltage to the motor terminals and rms current measurements. The advantages include simplicity and minimal equipment requirement. Other standstill tests rely on the current response to dc step voltage excitation, and require instantaneous rather than rms measurements [11]-[14]. Some of the limitations of the tests conducted at standstill conditions are that slot harmonics and core loss effects are not fully considered. These effects can be accounted for in tests under running conditions described for example in [4], [15]-[17]. Some other variants of these approaches have been proposed in previous studies [18]-[22].

Nehl et al. reported a network model in the abc stationary reference for permanent magnet synchronous and brushless DC machines in an early work [23]. The parameters were obtained from finite element analysis, and were used to simulate the interaction between a $15 \mathrm{hp}$ motor and its power converter, and excellent agreement with the waveforms from simulation and experiment was observed. The same group of authors calculated self and mutual incremental inductances including the effect of saturation using finite element analysis for the same machine, for a more accurate prediction of the dynamic behavior [24]. Stirban et al. also discuss the calculation of saturated self as well as mutual inductances using finite element analysis [25]. In this work, only one phase was excited with dc current, and the inductances, referred to as normal and transient, were calculated as the ratio of flux to the current, and flux change to the current change, respectively, for different rotor positions.

In this regard, other works have also discussed the performance characterization of PMSMs based on flux linkages, rather than inductances, for example Miller et. al proposed the use of flux-mmf diagrams for torque calculation of different motors in [26]. A similar approach, based on phase flux linkage-mmf diagrams was used by Jack et al. in the control of PMSM [27]. A full flux representation of a PMSM was also discussed in a more recent work [28].

Cross coupling and saturation effects have been discussed in works including [29] by Boldea, for wound rotor synchronous generators. In [30], Ionel et al. identified the inability to separate the contributions of PM flux and d-axis current to the d-axis flux. Online parameter estimation based on current injection, using linear equations to account for cross coupling and saturation have been discussed by Feng et al. [31]. The 
effect of cross coupling, and saturation was also noticed by Bolognani et al. to affect the accuracy of sensorless rotor position estimation techniques [32].

The work by Tessarolo et al. has studied the calculation of transient and subtransient inductances of wound rotor synchronous machines using finite element analysis, as well as tests based on sudden short circuit, and phase unbalance [33]. In a PMSM, due to the absence of damper windings, and owing to the large resistance of the magnets, the subtransient period may be considered to be absent, and the transient period very short [34].

A special note is due to a recently proposed method which relies on dc excitation and static torque measurements for the determination of the difference between $q-$ and $d-$ axes inductances, $L_{q}-L_{d}$ [35]. The value of $L_{d}$, for example, from a short circuit test, would allow $L_{q}$ to be determined separately. A general review of different methods for inductance testing is provided in [36]. Other work has been done to compare a few different approaches [4], [37]-[39].

This paper further expands on a previous conference paper by the same group of authors [40], and brings new contributions in terms of expanded mathematical formulation, methodological approach and experimental data. It reports one of the first studies systematically discussing different methods for inductance testing, particularly applicable for salient IPM machines. Virtual tests, i.e. computationally equivalent finite element models for different tests including short-circuit, open-circuit, ac standstill, dc step response, and full load are developed. Since each of the tests is representative of a particular operating condition, the $d q-$ parameters obtained from different tests have a spread of values. A critical and comparative analysis of the outcomes from different tests is provided, and recommendations on the tests to employ if the emphasis is on single parameter values are included. Studies and lab tests reported in this paper are conducted on an IPM motor with non-sinusoidal back emf, 9 stator slots, 6 rotor poles (Fig. 1a), relatively high torque ripple, and low leakage.

Additional contributions include the study of an alternative locked-rotor method based on dc current supply. This method involves static torque versus rotor position measurements and is introduced for determining $q$-axis inductance. The discussed method can be used in conjunction with the standardized open-circuit and short-circuit tests. It requires an in line torque transducer and provides a measurement of the torque capability without a power electronic drive. Another contribution involves deriving the relationships between the $d q-$ axes and line-line inductance obtained from different types of standstill tests.

The paper is organized as follows: Section II reviews the models commonly employed for IPM synchronous machines, and the open and short circuit tests as specified by the IEEE Std 1812 for inductance testing are discussed in Section III. Section IV discusses a proposed test for $q$ - axis inductance based on static torque measurements, and Section V, the relationship between the $d-$ and $q$-axes parameters, and the inductances measured from different tests. Different imple-

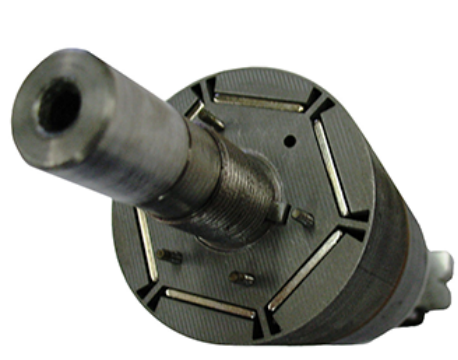

(a)

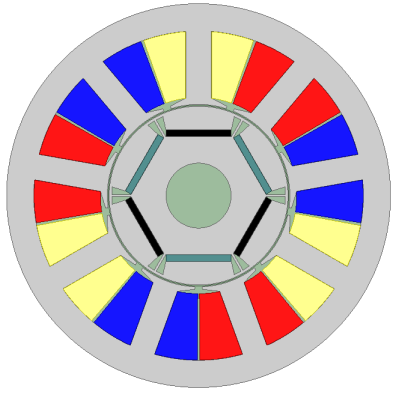

(b)
Fig. 1. The studied 9-slot 6-pole IPM motor (a) Rotor with step staggered skew, (b) cross section. The machine is rated for $9 \mathrm{Nm}$, and has a maximum speed of $3600 \mathrm{rpm}$. A machine with non-sinusoidal back emf, stagger skew, and relatively high torque ripple and a substantially long axial length so that leakage is low is considered for study.

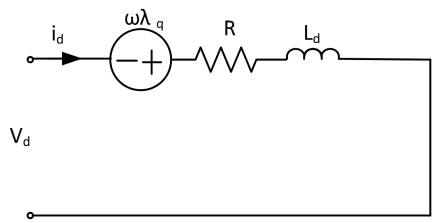

(a)

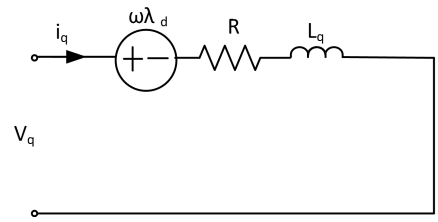

(b)
Fig. 2. The equivalent circuit diagrams in (a) $d$-axis and (b) $q$-axis.

mentations of the dc step response, and ac standstill tests are dealt with in Sections VI and VII. On load tests form the subject of discussion in Section VII, and a discourse on the relative magnitudes of parameters from different tests is provided in Section IX.

\section{REVIEW OF MODELS}

The voltage and torque equations at steady state for an IPM synchronous machine in the $d q-$ synchronously rotating frame which may be represented as equivalent circuits in Fig. 2, are given by:

$$
\begin{aligned}
& V_{d}=R I_{d}-\omega_{e} \psi_{q}, \\
& V_{q}=R I_{q}+\omega_{e} \psi_{d}, \\
& T_{e m}=\frac{3 p}{2}\left(\psi_{d} I_{q}-\psi_{q} I_{d}\right),
\end{aligned}
$$

where $V_{d}, V_{q}, I_{d}, I_{q}, \psi_{d}, \psi_{q}$, are the $d$ - and $q$ - axes voltages, currents, and flux linkages, respectively; $\omega_{e}$, the electrical frequency; $T_{e m}$, the electromagnetic torque; and $p$, the number of pole pairs. In the simplest case, saturation is neglected and the parameters $\psi_{d}$ and $\psi_{q}$ are given by:

$$
\psi_{d}=L_{d} I_{d}+\psi_{m}, \psi_{q}=L_{q} I_{q},
$$

where $\psi_{m}$ is the PM flux. Single values of the inductances $L_{d}$ and $L_{q}$ exist as per the simplified model. The equation (2) assumes that the effect of $i_{d}$ on $\psi_{m}$ is included in the $d$ - axis inductance. The contributions of the permanent magnet and $i_{d}$ to the $d-$ axis flux are unseparated as per this equation [30]. In the more general case, saturation and cross coupling effects 

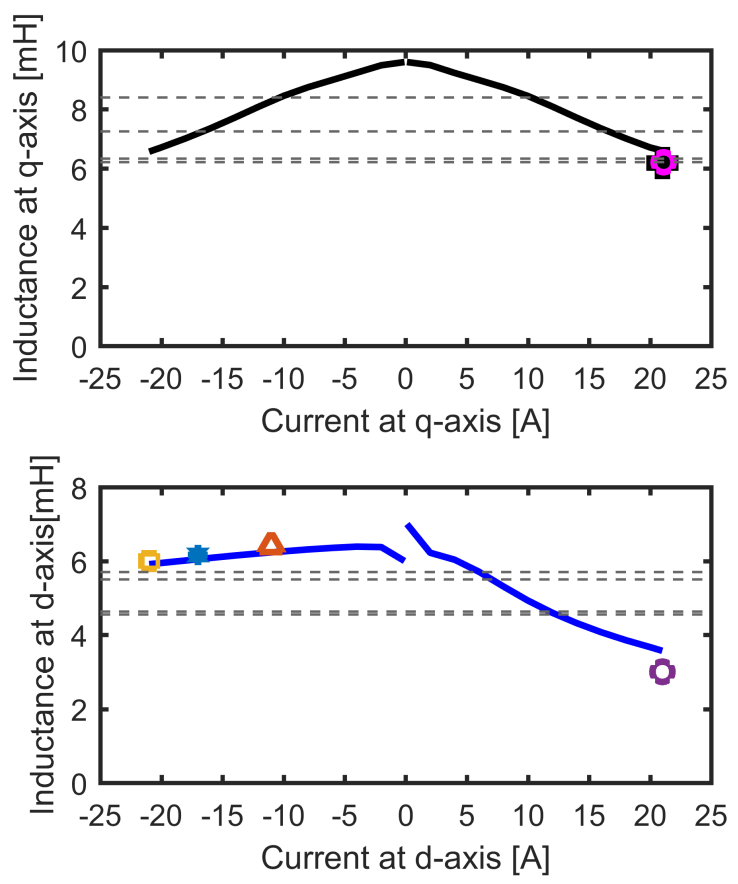

Fig. 3. Variation of the $d$-axis inductance with the $d$-axis current, and of the $q$-axis inductance with the current in the $q$-axis. The $d$-axis inductance is substantially affected by saturation, with its value reducing to half under the conditions of rated magnetization. The solid line represents the FEA results and the markers point to the inductance values obtained from different tests and measurements. The dashed lines represent the values from the standstill tests, for which no $d q$ currents can be defined.

are considered such that both $\psi_{d}$ and $\psi_{q}$ are functions of $I_{d}$ and $I_{q}$ [41], [42]. In this regard, some authors have defined a "Total Flux Representation", with the phase flux linkage and torque defined through FEA simulations, as a function of rotor angle, for different values of stator currents. In a more pragmatic approach, the effect of $I_{d}$ on $\psi_{q}$ is considered to be negligible, and the cross-coupling effect is reflected in the dependence of $\psi_{m}$ on $I_{q}$ [43], [44]. Including saturation, thus the following relations may be written:

$$
\psi_{m}=f\left(I_{q}\right), L_{d}=f\left(I_{d}\right), L_{q}=f\left(I_{q}\right) .
$$

Finite element simulations on the 9-slot 6-pole IPM of Fig. 1 are used to examine the dependence of $L_{d}$ on $I_{d}$ and $L_{q}$ on $I_{q}$ (Fig. 3). In the convention adopted in this paper, a negative value of $I_{d}$ implies that the armature flux opposes the PM field, and a positive value is indicative of aiding PM and armature fields. Likewise, a positive and negative $I_{q}$ is representative of operation in the motoring and generating modes, respectively. In line with expectations, the inductance $L_{q}$ is independent of the polarity of $I_{q}$. On the other hand, due to the demagnetizing effect, $L_{d}$ is higher at negative values of $I_{d}$. With positive $I_{d}$, the magnetic circuit is saturated due to the additive effects of PM and armature flux, resulting in reduced $L_{d}$.

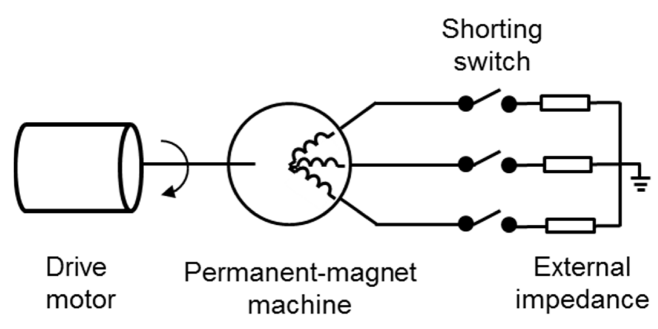

(a)

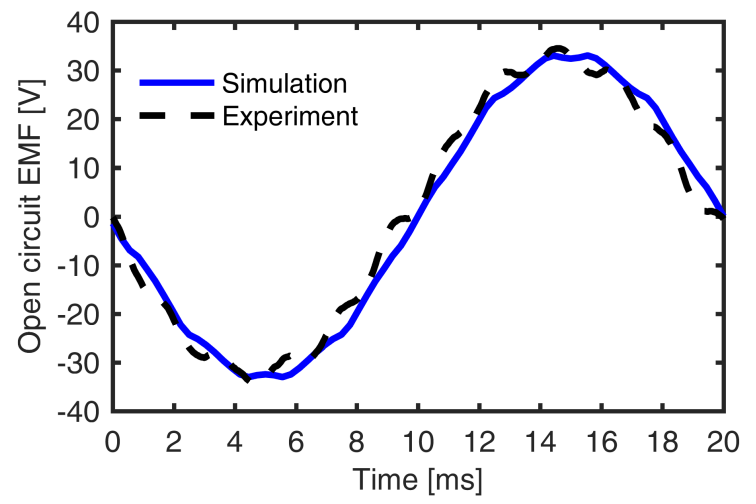

(b)

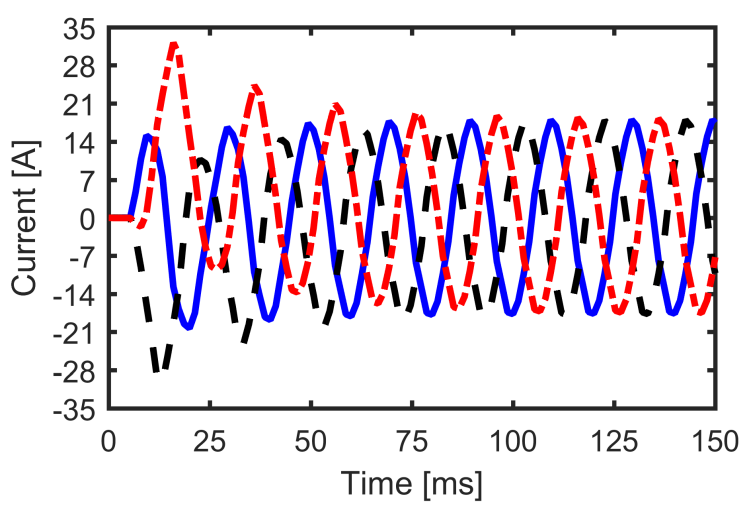

(c)

Fig. 4. (a) Open and short-circuit test configuration based on IEEE Std 1812 [1],(b) Simulated and measured back emfs at $1000 \mathrm{rpm}$, and (c) Simulated three phase currents when an uncontrolled short-circuit is applied at $t=16.66$ ms.

\section{Open And Short Circuit Tests AcCording to THE IEEE STD 1812}

Equivalent circuit parameters required from a PM machine are $L_{d}, L_{q}$, and the PM flux linkage on open-circuit. In order to determine the PM flux linkage on open-circuit, a drive motor is used to bring the PMSM up to the desired test speed (Fig. 4a). The results are presented in Fig. 4b. Following the measurement of open-circuit voltage, the machine is shortcircuited by closing the contactor represented in Fig. 4a, and the current is measured at steady state. The PM flux linkage, 


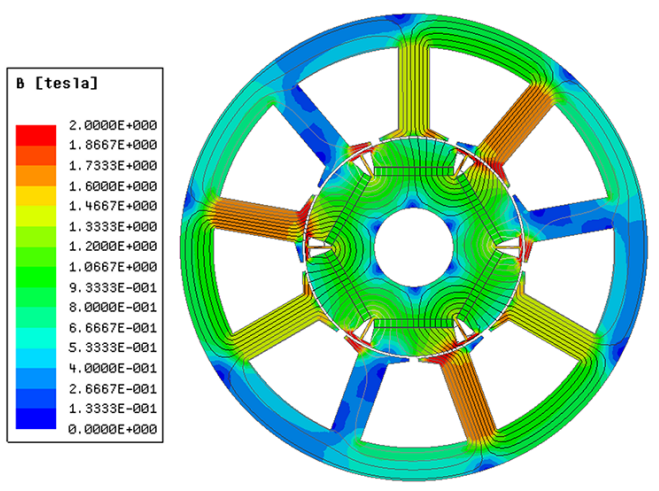

(a)

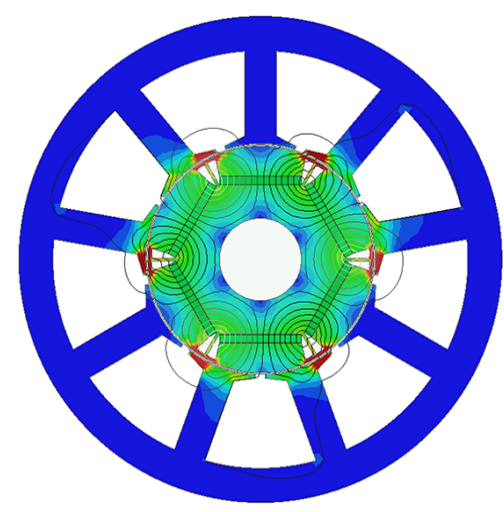

(b)

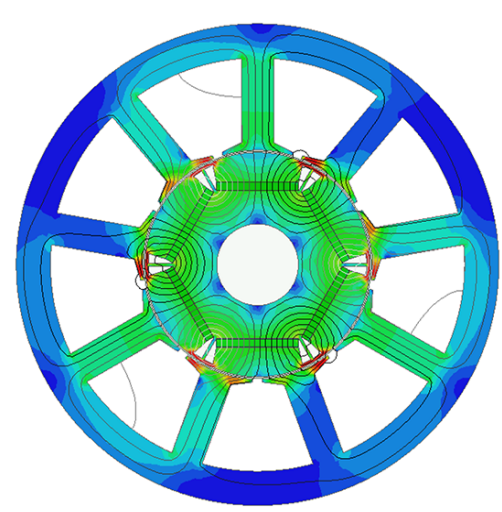

(c)

Fig. 5. Flux lines at (a) the rated load operating condition. (b) uncontrolled short circuit, with steady current equal to approximately $23 \mathrm{~A}$ rms, and (c) at a controlled short circuit condition with current limited to $11 \mathrm{~A}$ by the addition of an external impedance. Very low values of the flux density and the PM rotor flux lines substantially closing through the air-gap and tooth tips of the stator due to the demagnetizing effect of the short circuit current may be noted.

$\psi_{m}$, and $d$-axis inductance, $L_{d}$, are obtained using:

$$
\begin{aligned}
& \psi_{m}=\frac{E_{o c}}{2 \pi f}, \quad Z=\frac{V_{o c}}{I_{s c}}, \\
& X_{d}=\sqrt{Z^{2}-R^{2}}, \quad L_{d}=\frac{X_{d}}{2 \pi f},
\end{aligned}
$$

where $E_{o c}$ is the peak value of the open-circuit voltage; $V_{o c}$, the rms value of the open-circuit voltage; $I_{s c}$, the rms value of the short-circuit current; $X_{d}$, the $d$-axis reactance; $R$, the phase resistance, and $f$, the electrical frequency. The phase resistance can be obtained by monitoring the short-circuit power, or by measurements from a multimeter. The value of $\psi_{m}$ obtained from a laboratory open circuit test is $0.107 \mathrm{~Wb}$, which is comparable to the value from a virtual test set up in ANSYS Maxwell ${ }^{\circledR}$ Finite Element Analysis (FEA) software.

The inductance obtained using (4) is the d-axis inductance, as a three-phase symmetrical short circuit corresponds to a pure d-axis excitation, if phase resistance is considered to be negligible. A virtual short-circuit test on the IPM of Fig. 1 is conducted in ANSYS Maxwell (Fig. 4c). The connection of an external impedance in series with the phases leads to a reduction in the short-circuit current. Such an approach can be used to obtain the variation of the d-axis inductance with demagnetizing $d$-axis current. It should be ensured that the connected impedance is reactive in nature, as the addition of a resistance would result in both $d$ and $q$ axis currents, and modifications should be made to (4) in such a situation. It may be mentioned that the lower flux density during short-circuit than on load (Fig. 5) could lead to an over-estimation of $L_{d}$.

\section{STATiC TESTS For TORQUe AND Q-AXIS INDUCtANCE}

With the use of other methods for e.g. the short-circuit test to determine the $d$-axis inductance, a static torque measurement can be used in order to obtain the $q$-axis inductance. The phases may be connected as shown in Fig. 6a or Fig. 6b. DC current is then supplied to the phases. The connection of Fig. 6a with $I_{b}=I_{c}=\frac{-I_{a}}{2}$, results in an MMF parallel to the phase $\mathrm{A}$ axis and the rotor rotates to align its $d$-axis with

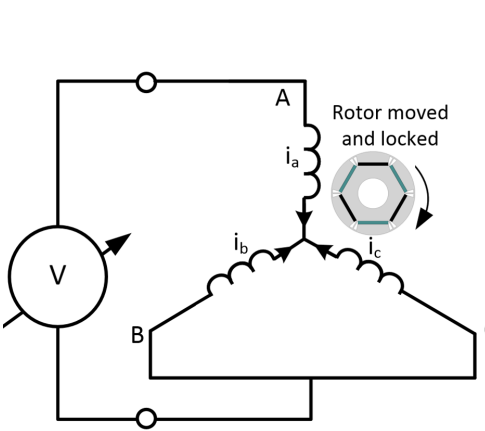

(a)

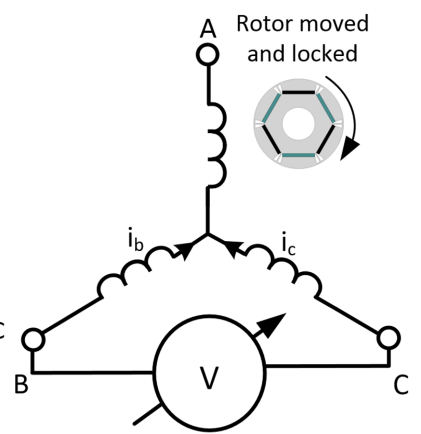

(b)
Fig. 6. Circuit connections with (a) Phase A connected in series with the parallel combination of Phases B and C, and voltage applied between phases $\mathrm{A}$ and $\mathrm{B}$. The resultant MMF is oriented along the axis of phase A, and the rotor rotates to align its $d$-axis along it ( $\mathrm{Cx} 3 \mathrm{ph})$ and $\mathrm{b}$ ) voltage applied across phases $\mathrm{B}$ and $\mathrm{C}$, resulting in an MMF perpendicular to the phase $\mathrm{A}$ axis $(\mathrm{Cx} 2 \mathrm{ph})$. If the rotor is held locked in the previous position in Fig. 6a, this is a $q$-axis excitation.

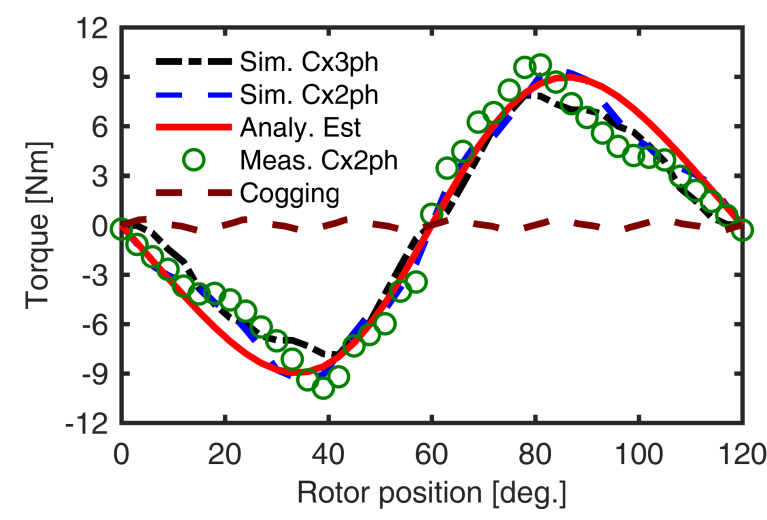

Fig. 7. de supply static torque measured and simulated with a virtual test procedure. For experiments an in-line torque transducer is required between the shaft and a mechanical locking device. The value of $L_{q}-L_{d}$ which best approximates the torque for the region of interest, i.e. with negative $I_{d}$, from 30 to 90 mechanical degrees, is found to be $1.4 \mathrm{mH}$. 
it. On the other hand, if the phases are connected as shown in Fig. $6 \mathrm{~b}$, the currents are $I_{b}=-I_{c}$, and $I_{a}=0$ and it results in a $q$-axis excitation, with the rotor held in the same position. The static torque is measured by locking the rotor in different intermediate positions (Fig. 7).

The value of the permanent magnet flux linkage $\psi_{m}$, can be obtained by holding the rotor in the $q$-axis position as:

$$
\psi_{m}=\frac{2 T_{m}}{3 p I_{q}},
$$

where $T_{m}$ is the measured torque and $p$, the number of pole pairs. The effect of cross coupling can be taken into account by using (5) to calculate $\psi_{m}$ from torque measurements at the $q-$ axis position at different values of the input dc current. With the value of $L_{d}$ from short circuit, $L_{q}$ may be determined using:

$$
L_{q}=L_{d}+\frac{\psi_{m}}{I_{d}}-\frac{2 T_{m}}{3 p I_{d} I_{q}},
$$

In principle, locking the rotor in two intermediate positions, including the $q$-axis is enough to determine $L_{q}$. However, $L_{q}$ is a function of $I_{q}$, which varies with changing rotor position. Moreover, owing to the effect of cogging torque and space harmonics, the variation of static torque with position is different from predicted by (1), therefore, this approach may not yield meaningful results (Fig. 7). In order to mitigate this limitation, the torque is measured with a resolution of 1-mechanical degree, over a pole pitch, and also calculated analytically. The root mean square error, $e$, between estimated and actual torques, $T_{e s t}$ and $T_{m}$, respectively, is found as:

$$
e=\sqrt{\frac{1}{n} \sum\left(T_{e s t}-T_{m}\right)^{2}},
$$

where $n$ is the number of sampled points. $T_{\text {est }}$ is replaced by $\frac{3}{2} \frac{p}{2}\left[\psi_{m} I_{q}+\left(L_{d}-L_{q}\right) I_{d} I_{q}\right]$ where $\psi_{m}$ is obtained from (5). The value of $L_{q}-L_{d}$ is selected to be the one which minimizes the root mean square of error between the measured and analytically estimated torques, as given in (7), over 180 electrical degrees corresponding to negative $I_{d}$ values. After obtaining the value for $L_{d}-L_{q}$, a single value of $L_{q}$ may be approximated, using the value of $L_{d}$ from the short circuit test. In this study, the value of $L_{q}$ thus obtained comes out to be $7.5 \mathrm{mH}$.

An alternative method involves holding the rotor stationary and injecting different values of $I_{a}, I_{b}$ and $I_{c}$, which can be done using an inverter. Since PMSMs are generally provided with drives, this method adds no extra cost. If the neutral is accessible, dc excitation may be used instead of the inverter. Considering that all measurements as described in this approach are conducted with the rotor held only at one position, it is likely to be less affected by cogging torque and space harmonics.

\section{The Relation between Line-Line, D And Q Axes INDUCTANCES}

Most laboratory tests for inductance measurement rely on locked rotor measurements at different positions with the application of $\mathrm{dc}$ or $1 \mathrm{ph}$ ac voltage to the phases connected as shown in Fig. 6. In these cases, with fixed voltage applied to the windings, the current would vary with rotor position due to the position dependent self and mutual inductances, approximately expressed as:

$$
\begin{aligned}
& L_{a}=L_{l}+L_{o}+L_{1} \cos (2 \theta), \\
& L_{b}=L_{l}+L_{o}+L_{1} \cos \left(2 \theta+120^{\circ}\right), \\
& L_{c}=L_{l}+L_{o}+L_{1} \cos \left(2 \theta-120^{\circ}\right), \\
& M_{a b}=M_{b a}=M_{o}+M_{1} \cos \left(2 \theta-120^{\circ}\right), \\
& M_{b c}=M_{c b}=M_{o}+M_{1} \cos (2 \theta), \\
& M_{c a}=M_{a c}=M_{o}+M_{1} \cos \left(2 \theta+120^{\circ}\right),
\end{aligned}
$$

where $L_{a}, L_{b}, L_{c}$ are the phase self inductances; $M_{a b}, M_{b c}, M_{c a}$ the mutual inductances; $\theta$, the rotor position with respect to the mmf-axis of phase $\mathrm{A}, L_{l}$, the leakage inductance, and $L_{1}, L_{o}$, the ac and dc components of the phase inductance respectively, and $M_{o}, M_{1}$, the dc and ac components of the mutual inductance. For a three-phase machine with sinusoidally distributed windings, $M_{o}=-\frac{L_{o}}{2}$ and $M_{1}=L_{1}$. However, space harmonics change the values of $M_{o}$ and $M_{1}$, and considering the rich harmonic content of fractional slot PMSM machines, the more general case is studied here.

The line-line inductance, $L_{l l}$ can be obtained by measuring voltages and currents. The relationship between the line-line inductance and the $d$ - and $q$-axes values depends on the circuit configuration employed. The circuit connection shown in Figs. $6 a$ and $6 \mathrm{~b}$ will be referred to as $\mathrm{Cx} 3 \mathrm{ph}$ and $\mathrm{Cx} 2 \mathrm{ph}$, respectively.

\section{A. Obtaining Inductances from Cx3ph}

In the case of the circuit connections of Fig. $6 \mathrm{a}, i_{b}=i_{c}=$ $-\frac{i_{a}}{2}$, and the $d-$ and $q-$ axes currents are given by:

$$
i_{d}=i_{a} \cos (\theta), \quad i_{q}=i_{a} \sin (\theta) .
$$

The flux linkages in the abc frame are:

$$
\begin{aligned}
\psi_{a} & =i_{a}\left[\left(L_{l}+L_{o}-M_{o}\right)+\left(L_{1}+\frac{M_{1}}{2}\right) \cos 2 \theta\right]+\psi_{m} \cos (\theta), \\
\psi_{b} & =i_{a}\left[\frac{\left(M_{o}-L_{l}-L_{o}\right)}{2}+M_{1} \cos \left(2 \theta-120^{\circ}\right)\right. \\
& \left.-\frac{M_{1}}{2} \cos (2 \theta)-\frac{L_{1}}{2} \cos \left(2 \theta+120^{\circ}\right)\right]+\psi_{m} \cos \left(\theta-120^{\circ}\right), \\
\psi_{c}= & i_{a}\left[\left(M_{o}-L_{l}-L_{o}\right) / 2+M_{1} \cos \left(2 \theta+120^{\circ}\right)\right. \\
& \left.-\frac{M_{1}}{2} \cos (2 \theta)-\frac{L_{1}}{2} \cos \left(2 \theta-120^{\circ}\right)\right]+\psi_{m} \cos \left(\theta+120^{\circ}\right) .
\end{aligned}
$$

The $d q-$ axes flux linkages are obtained upon transformation of (10) as follows:

$$
\begin{aligned}
& \psi_{d}=i_{a} \cos (\theta)\left[\left(L_{l}+L_{o}-M_{o}+\frac{L_{1}}{2}+M_{1}\right]+\psi_{m}\right. \\
& \psi_{q}=i_{a} \sin (\theta)\left[\left(L_{l}+L_{o}-M_{o}-\frac{L_{1}}{2}-M_{1}\right] .\right.
\end{aligned}
$$


Using (9) and comparison of (11) with (2) gives:

$$
\begin{aligned}
& L_{d}=L_{l}+L_{o}-M_{o}+\frac{L_{1}}{2}+M_{1}, \\
& L_{q}=L_{l}+L_{o}-M_{o}-\frac{L_{1}}{2}-M_{1} .
\end{aligned}
$$

The line-line inductance, $L_{l l}$ is defined as:

$$
V_{a b}=V_{a}-V_{b}=L_{l l} \frac{d i_{a}}{d t} .
$$

Based on voltage equations in the abc frame, it can be proved that:

$L_{l l}=\frac{3}{2}\left(L_{l}+L_{o}-M_{o}\right)+\left(\frac{L_{1}}{2}+M_{1}\right)\left[\cos (2 \theta)-\cos \left(2 \theta \pm 120^{\circ}\right)\right]$

Putting $\theta=0^{\circ}$ and $\theta=90^{\circ}$ in (14), and using (12) gives the values of $L_{d}$ and $L_{q}$ :

$$
L_{0}=\frac{3}{2} \cdot L_{d}, \quad L_{90}=\frac{3}{2} \cdot L_{q},
$$

where, $L_{0}$ and $L_{90}$ are the line-line inductances with the rotor's $d$-axis aligned along and perpendicular to the MMF axis of phase A, respectively. This analysis indicates that for the circuit connection of Fig. 6a, multiplying the line inductance by $\frac{2}{3}$ when the rotor's $d$-axis is aligned with and perpendicular to the magnetic axis of phase A give the $d-$ and $q-$ axes inductances, respectively.

\section{B. Obtaining Inductances from $\mathrm{Cx} 2 \mathrm{ph}$}

In another implementation of this method, the windings may be connected as shown in Fig. 6 b. In this case, the relation between the phase currents is: $i_{b}=-i_{c}, i_{a}=0$, and the currents in the $\mathrm{d}$ and q-axes are:

$$
\begin{aligned}
i_{d} & =\frac{2}{3} i_{b}\left[\cos \left(\theta-120^{\circ}\right)-\cos \left(\theta+120^{\circ}\right)\right], \\
i_{q} & =\frac{2}{3} i_{b}\left[\sin \left(\theta-120^{\circ}\right)-\sin \left(\theta+120^{\circ}\right)\right] .
\end{aligned}
$$

The following relations for abc flux linkages may be written:

$$
\begin{aligned}
\psi_{a}= & i_{b}\left[M_{1} \cos \left(2 \theta-120^{\circ}\right)-M_{1} \cos \left(2 \theta+120^{\circ}\right)\right] \\
& +\psi_{m} \cos (\theta), \\
\psi_{b}= & i_{b}\left[L_{l}+L_{o}+L_{1} \cos \left(2 \theta+120^{\circ}\right)-M_{o}-M_{1} \cos (2 \theta)\right] \\
& +\psi_{m} \cos \left(\theta-120^{\circ}\right), \\
\psi_{c}= & i_{b}\left[M_{o}+M_{1} \cos (2 \theta)-L_{l}-L_{o}-L_{1} \cos \left(2 \theta-120^{\circ}\right)\right] \\
& +\psi_{m} \cos \left(\theta+120^{\circ}\right) .
\end{aligned}
$$

The $d q$ frame flux linkages are found by transformation of (17) as:

$$
\begin{aligned}
\psi_{d}= & \frac{2}{3} i_{b}\left[( \operatorname { c o s } ( \theta - 1 2 0 ^ { \circ } ) - \operatorname { c o s } ( \theta + 1 2 0 ^ { \circ } ) ) \left(L_{l}+L_{o}-M_{o}\right.\right. \\
& \left.\left.+\frac{L_{1}}{2}+M_{1}\right)\right]+\psi_{m}, \\
\psi_{q}= & \frac{2}{3} i_{b}\left[( \operatorname { s i n } ( \theta - 1 2 0 ^ { \circ } ) - \operatorname { s i n } ( \theta + 1 2 0 ^ { \circ } ) ) \left(L_{l}+L_{o}-M_{o}\right.\right. \\
& \left.\left.-\frac{L_{1}}{2}-M_{1}\right)\right] .
\end{aligned}
$$

TABLE I

PARAMETERS FROM THE OC/SC AND DC-STEP RESPONSE VIRTUAL TESTS USING CX2PH AND CX3PH. THE VALUE OF $L_{d-}$, I.E. $d-$ AXIS INDUCTANCE AT THE DEMAGNETIZING POSITION IS APPROXIMATELY EQUAL TO THE VALUE OF $L_{d}$ FROM THE SHORT CIRCUIT TEST.

\begin{tabular}{lrrrrr}
\hline Method & $L_{d+}[\mathrm{mH}]$ & $L_{d-}[\mathrm{mH}]$ & $L_{d}[\mathrm{mH}]$ & $L_{q}[\mathrm{mH}]$ & $\psi_{m}[\mathrm{mWb}]$ \\
\hline OC/SC & N/A & N/A & 6.16 & N/A & 0.101 \\
Cx3ph & 3.20 & 5.67 & 4.44 & 6.18 & N/A \\
Cx2ph & 2.99 & 6.02 & 4.50 & 6.34 & N/A \\
\hline
\end{tabular}

Comparing with (2), it may be observed that the relationship between the $d q-$ axes inductances and the terms in the self and mutual inductance series for this case is the same as for $\mathrm{Cx} 3 \mathrm{ph}$, given by (12), in line with expectations from the analysis in [45].

The line-line inductance in this case is:

$$
L_{l l}=\left[2\left(L_{l}+L_{o}-M_{o}\right)-\left(L_{1}+2 M_{1}\right) \cos (2 \theta)\right] .
$$

$L_{d}$ and $L_{q}$ can be found by substituting $\theta=0$ and $\theta=90^{\circ}$ in (19) to be:

$$
L_{q}=\frac{L_{0}}{2}, \quad L_{d}=\frac{L_{90}}{2},
$$

where $L_{0}$ is the line inductance when the rotor $d$-axis is aligned with the axis of phase $\mathrm{A}$, and $L_{90}$ is the line inductance when the rotor $q$-axis is aligned with the axis of phase A.

\section{DC Step Response Tests}

The inductance can also be determined by observing the stator current response, rise or decay, to a step change in voltage, which may be applied for example, by using an inverter [12]-[14]. The rotor is locked in the $d-$ and $q-$ axes positions using the circuit connection of Fig. $6 \mathrm{a}$ or $6 \mathrm{~b}$. The current in response to a positive voltage step is given by the following:

$$
I=\frac{V}{R_{e q}}\left(1-e^{\frac{-R_{e q} t}{L}}\right),
$$

where $V$ is the applied dc voltage; $I$, the current response; $\mathrm{L}$, the line-line inductance at the corresponding rotor position, and $R_{e q}$, the equivalent resistance which depends on the method of circuit connection. The value of the phase resistance is determined from the steady state value of the current, and the value of $\mathrm{L}$ may then be subsequently determined from (21) by curve fitting, knowing the instantaneous values of current. The $d-$ and $q-$ axes inductances are obtained by multiplying $\mathrm{L}$ at these positions by $\frac{2}{3}$ or $\frac{1}{2}$ depending on the circuit connection applied.

Results from the virtual test for the circuit connections of Fig. 6 can be seen in Fig. 8 and the values obtained, in Table I. The dc-step response test conducted at two consecutive d-axes, designated as $L_{d+}$ and $L_{d-}$ yields different values of inductance, as the current at one of these positions is magnetizing, and demagnetizing at the other, and the value reported as $L_{d}$ for this method is obtained by taking an average of these two. 


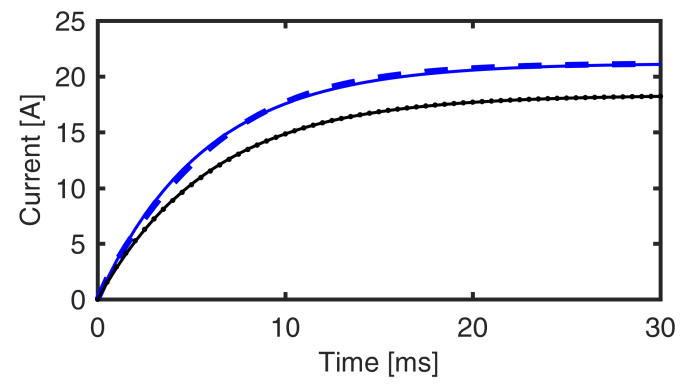

(a)

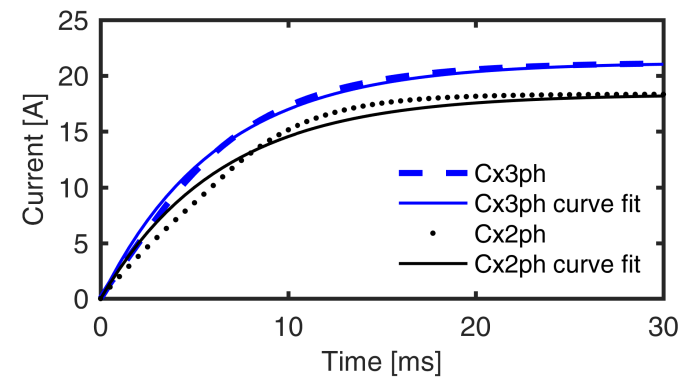

(b)

Fig. 8. Currents obtained from a virtual dc-step response test at (a) d and (b) qaxis positions. The inductance is obtained from curve fitting the instantaneous current.

\section{INDUCTANCE FROM STANDSTILl TESTS}

A method commonly used in the industry for inductance estimation of PMSMs involves locking the rotor at different positions and connecting the phases using either Fig. 6a or $6 \mathrm{~b}$ [2], [5], [6], [11]. Voltage is applied to the phases, and the line-line inductance with the rotor locked at different positions is then obtained from equations similar to (4).

The inductances obtained by estimation from measurement are compared with those obtained from a virtual standstill test set up in FEA software. The inductance profiles as obtained from virtual tests conducted with the phases connected as per Cx3ph and Cx2ph are compared (Fig. 9a). Tests in the lab are performed for $\mathrm{Cx} 2 \mathrm{ph}$, and comparison between the lab and virtual tests is seen in Fig. 9b.

The $d q-$ axes inductances can also be obtained by determining the terms in the inductance series, i.e. $L_{o}, M_{o}$, $L_{1}$ and $M_{1}$ in (8). Self and mutual inductances at different positions can be measured through a test in which $1 \mathrm{ph}$ ac voltage is applied to only phase A ( $\mathrm{Cx} 1 \mathrm{ph})$. The other phases are not excited, and it may be noted that this type of test would require access to the neutral point. The rotor is rotated and locked at different positions, and measurements include the current in the excited phase A, and the induced voltages in the unexcited phases. Resistance can be measured using a multimeter, and the self and mutual inductances are then obtained from equations similar to (4). Results from an equivalent virtual test in ANSYS Maxwell are seen (Fig. 10).
TABLE II

$d$ AND $q$ AXES INDUCTANCES FROM DIFFERENT IMPLEMENTATIONS OF THE AC STANDSTILL TEST.

\begin{tabular}{lcc}
\hline Method & $L_{d}[\mathrm{mH}]$ & $L_{q}[\mathrm{mH}]$ \\
\hline Cx3ph & 4.35 & 6.17 \\
Cx2ph & 4.63 & 6.32 \\
Cx2ph Meas. & 4.55 & 6.21 \\
Cx1ph & 4.53 & 7.04 \\
\hline
\end{tabular}

In this case it can be proved that the $d q-$ axes inductances are also given by (12). The terms $L_{o}, L_{1}, M_{o}$ and $M_{1}$ required for the $d q$ - inductances, can be found from the self and mutual inductances at different rotor positions from the following:

$$
L_{o}+L_{l}=\frac{L_{\max }+L_{\min }}{2}, L_{1}=\frac{L_{\max }-L_{\min }}{2},
$$

where $L_{\max }$ and $L_{\min }$ are the maximum and minimum inductances respectively. Similar expressions can be written for the terms $M_{o}$ and $M_{1}$. The $d$ and $q$ axes inductances obtained from the different methods are summarized, and are observed to be comparable (Table II).

In the ac standstill test, the d-axis current, on an average, is neither magnetizing nor demagnetizing, in contrast to the $\mathrm{dc}$ step response test. It may be observed that the average value of the inductances obtained from dc step response tests at two consecutive d-axis positions is close to the value $L_{d}$ from the ac standstill test (Table I, II).

A major drawback of the ac standstill test is that the magnetic field established within the electric machine is different from the rotating one, which is specific to the running operation (Figs. 11 and 12). On the other hand, dc excitation, can more accurately represent the relation between the stator and rotor fields during running conditions.

\section{ON LoAd Electronically Controlled Tests}

In addition to the real and virtual experiments described in the previous sections, the on-load performance of the motor under study has been measured at rated speed using a vector controlled power electronic drive and corresponding FE simulations have been conducted. Special set-ups included those for operation at the maximum torque per ampere (MTPA) condition and on-load with zero $d$-axis current (ID0). In such cases, using the value of $L_{d}$ derived from the short circuit test, the $q$-axis inductance and the PM flux linkage can be calculated as:

$$
L_{q}=\frac{V_{a} \sin \varphi}{2 \pi f I_{a}}, \quad \psi_{m}=\frac{2 T_{e m}}{3 p I_{q}},
$$

where $V_{a}$ and $I_{a}$ are the rms values of the fundamental harmonic of phase voltage and current, respectively, and $\varphi$ is the power factor angle.

Experiments and data post-processing require special care. For example, the electromagnetic torque, $T_{e m}$, is obtained by adding to the measured shaft torque, a component corresponding to all the motor power losses except the stator winding 

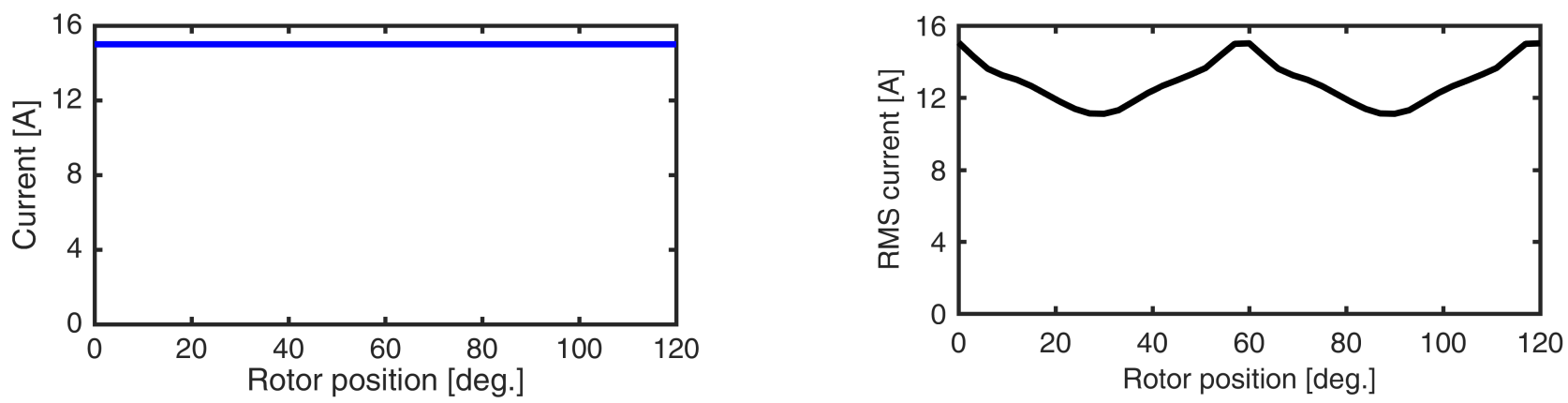

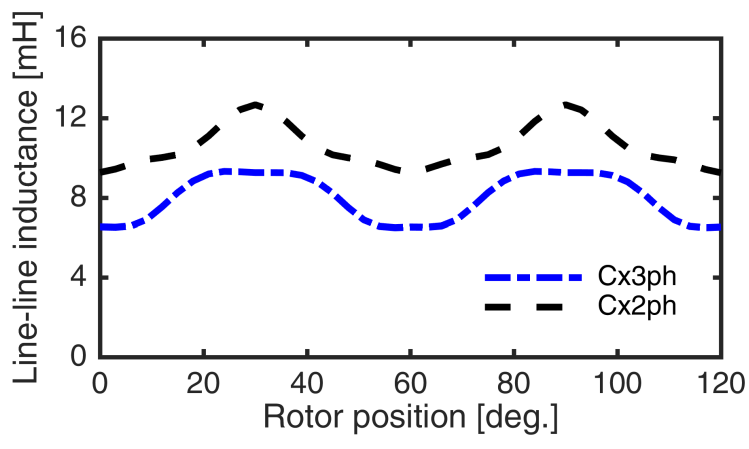

(a)

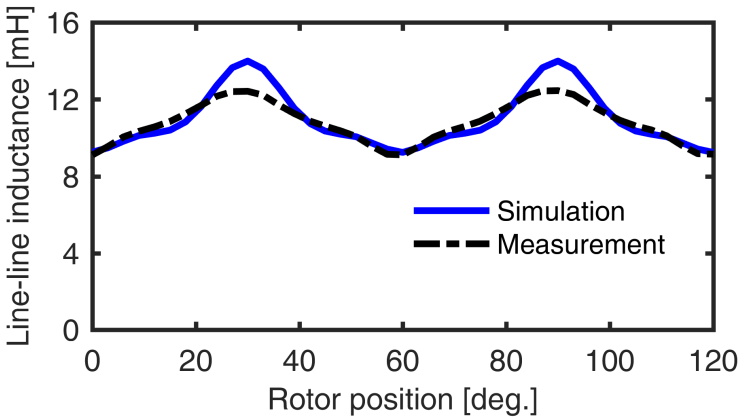

(b)

Fig. 9. (a) Line-line inductance for ac standstill tests in FEA with all 3 phases excited (Cx3ph) and only phases on (Cx2ph). The d and q inductances are obtained by multiplying the line-line inductance in those positions by $2 / 3$ and $1 / 2$ in the Cx3ph and Cx2ph case, respectively. (b) Measured and simulated line-line inductances obtained using the circuit connection $\mathrm{Cx} 2 \mathrm{ph}$. In the measured case, the test is voltage driven. The simulation study employs a position dependent driving current, which is obtained from the measurements.

TABLE III

$L_{d}, L_{q}$ AND $\psi_{m}$ AS OBTAINED FROM SIMULATION AND MEASUREMENTS. THE VALUE OF $L_{q}$ FROM EXPERIMENTS RELIES ON FILTERING THE VOLTAGE WAVEFORMS TO EXTRACT THE FUNDAMENTAL COMPONENTS, AND AN ESTIMATE OF THE ELECTROMAGNETIC TORQUE FROM DYNE MEASUREMENTS, AND IS THEREFORE NOT EQUAL TO THE VALUE FROM SIMULATION.

\begin{tabular}{lccc}
\hline Method & $\psi_{m}[\mathrm{mWb}]$ & $L_{d}[m H]$ & $L_{q}[\mathrm{mH}]$ \\
\hline On load IDO (sim.) & 0.10 & N/A & 6.24 \\
On load IDO (meas.) & 0.11 & N/A & 4.54 \\
MTPA (sim.) & N/A & 5.91 & 6.83 \\
\hline
\end{tabular}

losses. Under current regulated control, the PWM voltage supply waveform is highly distorted and has a rich high frequency harmonic content as illustrated in Fig. 14. Therefore, caution must be exerted in applying filtering techniques and measuring only the rms values and the power factor corresponding to the fundamental harmonic, in compliance with the principles of the $d q-$ theory.

Based on the FEA simulations, which are considering onload operation with specified values for the $d q-$ current components, the inductances are estimated as:

$$
L_{d}=\frac{\psi_{d}-\psi_{m}}{I_{d}}, \quad L_{q}=\frac{\psi_{q}}{I_{q}},
$$

where the PM flux linkage is a function of $I_{q}$. Parameter values derived based on on-load measurements and FE simulations are listed in Table III.

\section{Discussion}

A summary of the performance of the methods described throughout the paper is provided (Table IV). Before drawing any comparisons between the inductance and PM flux linkage values obtained from different methods, it should be acknowledged that magnetic saturation in IPM motors affects the values of $d q-$ parameters, which are, in principle, non-linear functions of the $d q-$ current components. Not only that there is a self-axis saturation that will cause the $d-$ and the $q$-axis inductances to be a function of the $d-$ and $q$-axis current, respectively, but there is also a cross-coupling saturation, that will cause for example the $d$-axis inductance and the on-load PM flux linkage to be a function of the $q$-axis current, as explained for example in [43].

Yet, in the current version of the IEEE Std 1812, the emphasis is placed on single parameter values for the $d$-axis parameters, which are calculated based on open-circuit and short-circuit tests. Although no single values for the $d q-$ parameters can be identified, some observations may be made. For instance, it is seen that the $d$ - axis inductance obtained from the ac-standstill test is the lowest, and in line with expectations, larger values are obtained in the short circuit test, and some cases of the dc tests. This may be attributed to the fact that the armature reaction at short circuit is largely 
TABLE IV

CAPABILITIES OF DIFFERENT INDUCTANCE MEASUREMENT METHODS.

\begin{tabular}{|c|c|c|c|c|c|c|}
\hline Method & Section & $L_{d}$ & $\begin{array}{c}\text { Measures } \\
L_{q}\end{array}$ & $\psi_{m}$ & $\begin{array}{l}\text { Includes the effects of } \\
\text { cross coupling }\end{array}$ & Example references \\
\hline $\mathrm{OC}$ and $\mathrm{SC}$ test & III & $\checkmark$ & $x$ & $\checkmark$ & $x$ & [1], [39] \\
\hline Singe phase ac standstill & $\mathrm{V}$ & $\checkmark$ & $\checkmark$ & $x$ & $x$ & {$[45],[46]$} \\
\hline $\mathrm{dc}$ step response & VI & $\checkmark$ & $\checkmark$ & $x$ & $x$ & {$[11]-[14]$} \\
\hline Static test & VII & $L_{d}$ & $L q$ is obtained & $\boldsymbol{v}$ & $v$ & [35], [47] \\
\hline ac standstill & VIII & $\checkmark$ & $\boldsymbol{\nu}$ & $x$ & $x$ & {$[2]-[10]$} \\
\hline On load electronically controlled & IX & $\checkmark$ & $\checkmark$ & $\boldsymbol{\sim}$ & $\boldsymbol{\nu}$ & {$[4],[48]$} \\
\hline
\end{tabular}

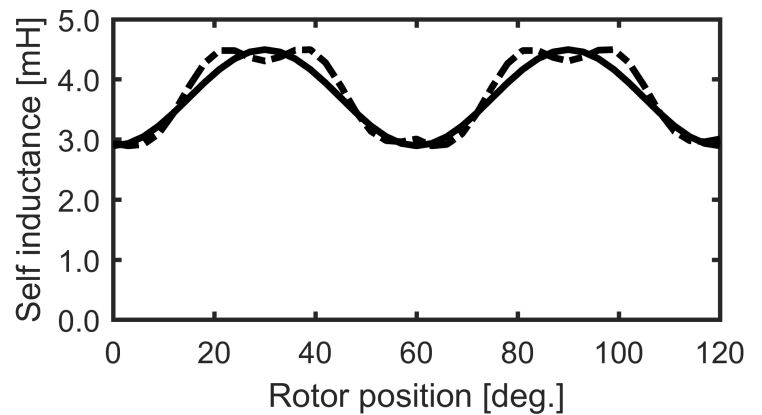

(a)

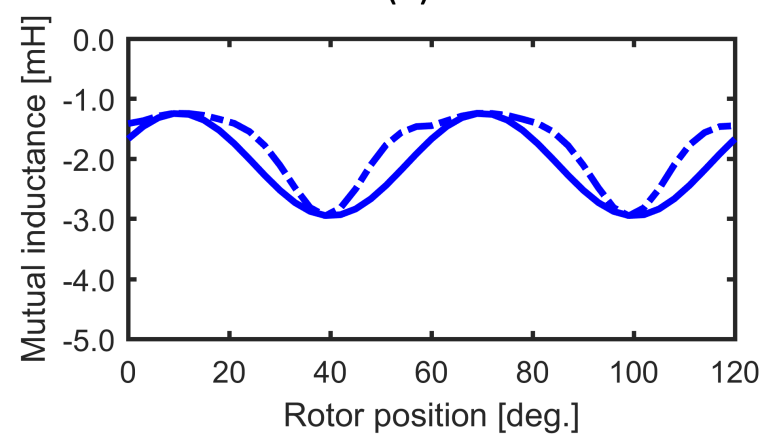

(b)

Fig. 10. (a) Self inductance, and (b) Mutual inductance along with the curve fit approximations, obtained from finite element analysis by exciting one phase with ac current. It is observed that $M_{o} \approx-\frac{L_{l}+L_{o}}{2}$ and $M_{1} \approx-L_{1}$.

demagnetizing, resulting in a linear magnetic circuit, and therefore larger inductance values. In contrast, an ac standstill test at the $d$-axis leads to a stationary, pulsating armature field, consequently, neither magnetizing nor demagnetizing, resulting in a value between the two extreme cases of magnetization and demagnetization as seen in Table II. In this regard, an interesting observation is that the $d$ - axis inductance obtained from the ac standstill test is very close to average value of inductances from the dc step response test conducted at two consecutive $d$-axes (Tables I and II).

It may also be noticed that the $q$-axis inductance as obtained from the ac standstill test is close to its value at the rated operating condition (Tables II and III). This can be explained
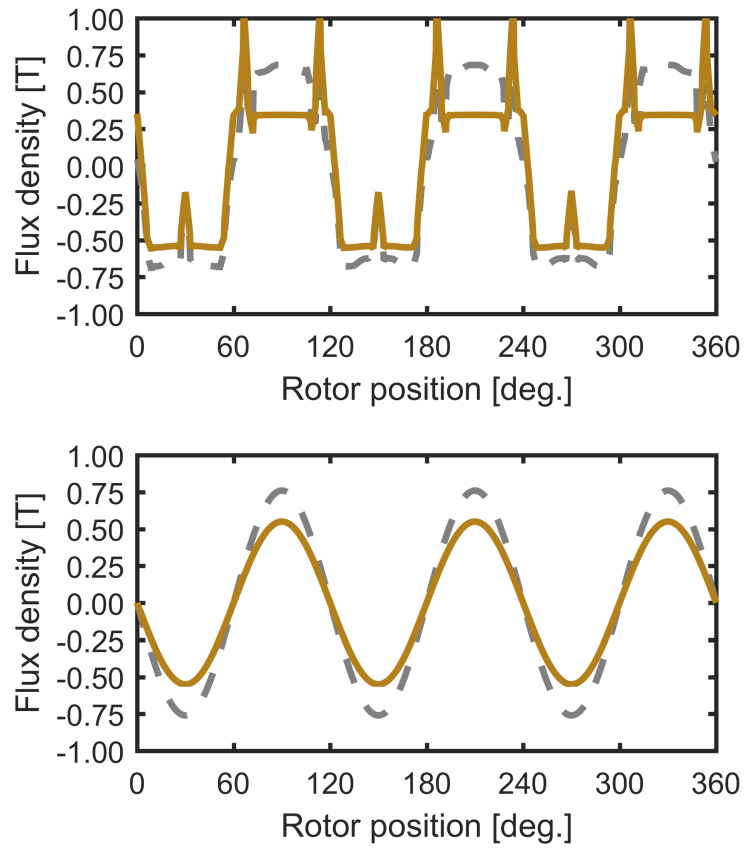

Fig. 11. Air gap flux density and its fundamental component of the radial air gap flux densities at different instants of time for the ac standstill test. The air-gap flux density in the standstill test is stationary and pulsating.

to some extent by considering that an ac standstill test at the $q$-axis represents an alternately positive and negative $q$-axis excitation. Since the $q$-axis flux is cross magnetizing, rather than demagnetizing, a positive or negative $q$-axis excitation would result in a similar field pattern, leading to the same inductance as obtained during running conditions with $I_{d}=0$.

In contrast with ac tests, in dc standstill tests, the fixed distribution of the stator currents and locked rotor position correspond to one "snap-shot" of the running on-load operation and rotating magnetic field pattern. In this regard, two types of dc static tests are proposed for the determination of $q$-axis inductance. One of these tests is simple, and can be conducted in the lab without requiring an inverter. This test can be employed in the case of a machine with little space harmonics and cogging torque. The second dc static test necessitates the use of an inverter, and is less affected by cogging torque. Both these methods are based on finding a 

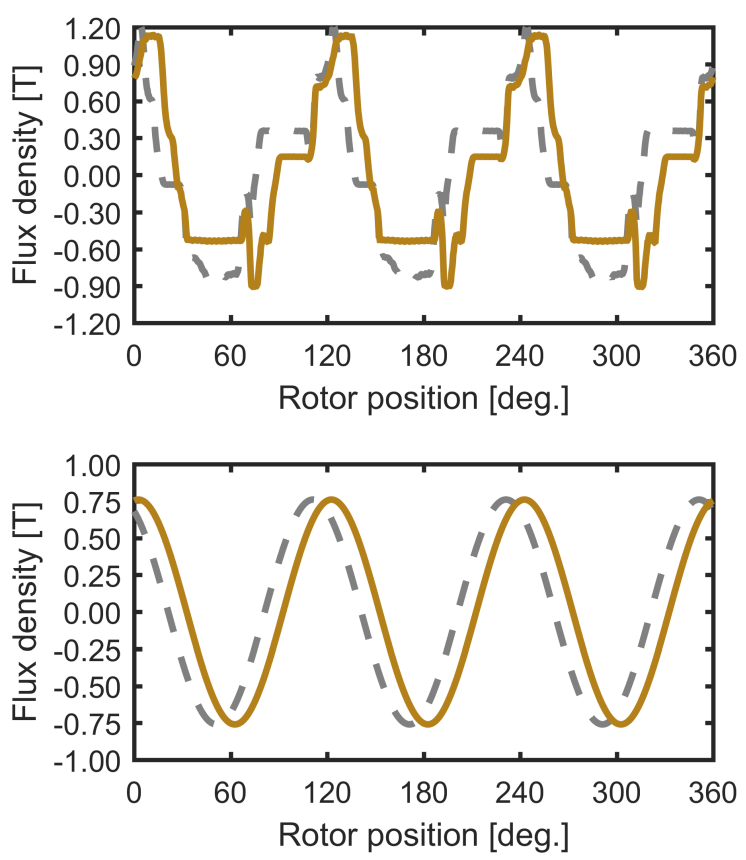

Fig. 12. Air gap flux density and its fundamental component of the radial air gap flux densities at different instants of time for the rated operation. The air-gap flux density is constant and shifts with time during rated operation.

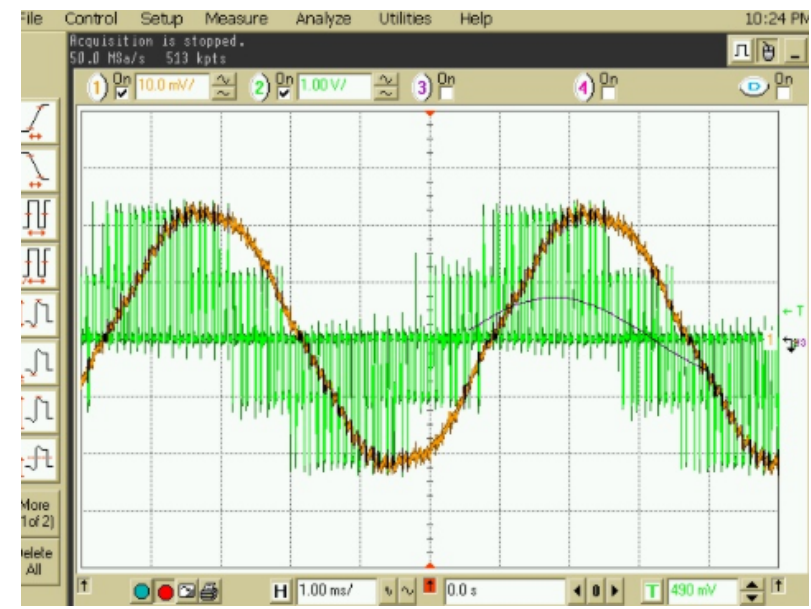

Fig. 13. Example of measured PWM voltage and electronically regulated current.

best-fit value of $L_{q}-L_{d}$, and other tests need to be used for $L_{d}$. These tests require precise torque measurements.

The dc-step response test conducted at the $q-$ axis, which also captures the correct relationship between the stator and rotor fields requires instantaneous current measurements, and owing to the variation of $q$-axis inductance with $q$-axis current, determining a single inductance value would be challenging. A best fit approach can be used, but the window over which curve fitting is to be done should be selected carefully.

If single values of the $d q-$ parameters are forced, the

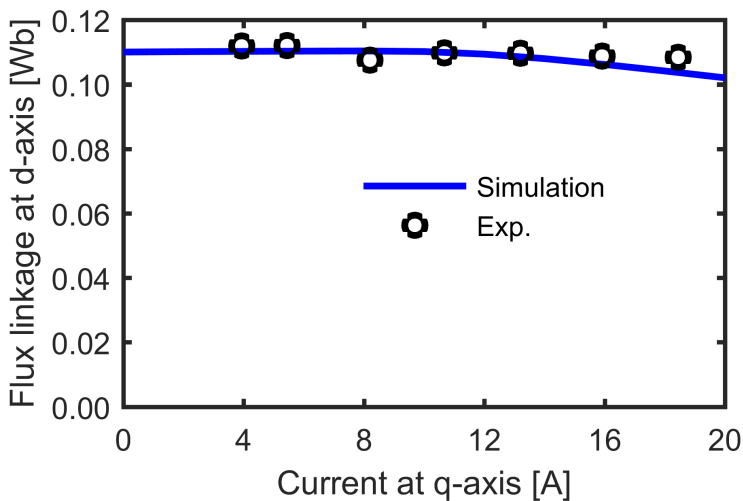

Fig. 14. The variation of the PM flux linkage with the $q$-axis current component, $I_{q}$, derived through FEA simulations for a motor model that considers the effect of self and cross-coupling saturation. The reported onload experimental results were obtained using a power electronic drive, which incorporates a control compensation for saturation.

inductance obtained from the ac standstill test conducted at the $q$-axis at rated current may be considered a fair enough estimate of $L_{q}$, in this case. Similarly, considering that IPM motors normally operate in the demagnetizing region, the inductance value from the short circuit test may be considered a reasonable estimate of $L_{d}$.

\section{CONCLusion}

Different approaches for measuring $d q-$ parameters of PM synchronous machines, particularly of the IPM type were discussed, including the use of the IEEE Std 1812 guidelines. The contributions of the paper include a critical review and the systematic comparison of various inductance measurement methods for IPM machines. An experimental and a two-dimensional FE computational study was conducted on an example IPM motor with low end effects. A full set of analytical equations for the calculation of the $d-$ and $q$-axis inductances from quantities obtained from standsill tests, including the effect of space harmonics were developed and reported. Further, locked-rotor methods in order to obtain $q-$ axis inductance are proposed.

Based on the results it was shown that more work is required in terms of expanding the scope of the IEEE Std 1812 with procedures for determining the $q$-axis inductance and, possibly, quantifying the non-linear saturation effects on all the parameters, both matters being of great interest especially for IPM machines.

\section{ACKNOWLEDGMENT}

The support of University of Kentucky, the L. Stanley Pigman endowment and the SPARK program, and of ANSYS Inc. is gratefully acknowledged.

\section{REFERENCES}

[1] "IEEE trial-use guide for testing permanent magnet machines," IEEE Std 1812-2014, pp. 1-56, Feb 2015. 
[2] "IEEE standard procedures for obtaining synchronous machine parameters by standstill frequency response testing -supplement to ANSI/IEEE Std 115-1983, IEEE guide: Test procedures for synchronous machines," IEEE Std 115A-1987, 1987.

[3] M. Musak and M. S. Tulrajter, "Novel methods for parameters investigation of PM synchronous motors." Acta Technica Corvininesis-Bulletin of Engineering, vol. 6, no. 1, 2013.

[4] H. B. Ertan and I. Sahin, "Evaluation of inductance measurement methods for PM machines," in Electrical Machines (ICEM), 2012 XXth International Conference on, Sept 2012, pp. 1672-1678.

[5] "AC Permanent Magnet Control Application Note," Yaskawa, Tech. Rep., 012009.

[6] J. Kang, "General Purpose Permanent Magnet Motor Drive without Speed and Position Sensor," Yaskawa, Tech. Rep., 072009.

[7] T. Sun, S. Kwon, J. Lee, and J. Hong, "An improved ac standstill method for testing inductances of interior PM synchronous motor considering cross-magnetizing effect," in 2009 IEEE Energy Conversion Congress and Exposition, Sept 2009, pp. 2415-2422.

[8] W. Soong, "Inductance measurements for synchronous machines," in Power Engineering Briefing Note Series 2, Oct 2008.

[9] E. S. Boje, J. C. Balda, R. G. Harley, and R. C. Beck, "Time-domain identification of synchronous machine parameters from simple standstill tests," IEEE Transactions on Energy Conversion, vol. 5, no. 1, pp. 164 175, March 1990.

[10] Y. Gao, R. Qu, and Y. Liu, "An improved ac standstill method for inductance measurement of interior permanent magnet synchronous motors," in 2013 International Conference on Electrical Machines and Systems (ICEMS), Oct 2013, pp. 927-931.

[11] V. Bobek, "PMSM electrical parameters measurement," Freescale Semiconductor Application Note, Tech. Rep., 012013.

[12] S. Weisgerber, A. Proca, and A. Keyhani, "Estimation of permanent magnet motor parameters," in Industry Applications Conference, 1997. Thirty-Second IAS Annual Meeting, IAS '97., Conference Record of the 1997 IEEE, vol. 1, Oct 1997, pp. 29-34 vol.1.

[13] M. Kazerooni, S. Hamidifar, and N. C. Kar, "Analytical modelling and parametric sensitivity analysis for the PMSM steady-state performance prediction," IET Electric Power Applications, vol. 7, no. 7, pp. 586-596, Aug 2013.

[14] B. Stumberger, G. Stumberger, D. Dolinar, A. Hamler, and M. Trlep, "Evaluation of saturation and cross-magnetization effects in interior permanent-magnet synchronous motor," IEEE Transactions on Industry Applications, vol. 39, no. 5, pp. 1264-1271, Sept 2003.

[15] K. M. Rahman and S. Hiti, "Identification of machine parameters of a synchronous motor," IEEE Transactions on Industry Applications, vol. 41, no. 2, pp. 557-565, March 2005.

[16] M. A. Rahman and P. Zhou, "Determination of saturated parameters of PM motors using loading magnetic fields," IEEE Transactions on Magnetics, vol. 27, no. 5, pp. 3947-3950, Sept 1991.

[17] H. P. Nee, L. Lefevre, P. Thelin, and J. Soulard, "Determination of $\mathrm{d}$ and $\mathrm{q}$ reactances of permanent-magnet synchronous motors without measurements of the rotor position," IEEE Transactions on Industry Applications, vol. 36, no. 5, pp. 1330-1335, Sept 2000.

[18] P. Niazi and H. A. Toliyat, "Online parameter estimation of permanentmagnet assisted synchronous reluctance motor," IEEE Transactions on Industry Applications, vol. 43, no. 2, pp. 609-615, March 2007.

[19] T. M. Jahns, S. Han, A. M. El-refaie, J. Baek, M. Aydin, M. K. Guven, and W. L. Soong, "Design and experimental verification of a $50 \mathrm{~kW}$ interior permanent magnet synchronous machine," in Conference Record of the 2006 IEEE Industry Applications Conference Forty-First IAS Annual Meeting, vol. 4, Oct 2006, pp. 1941-1948.

[20] A. Gebregergis, M. Islam, T. Sebastian, and R. Ramakrishnan, "Evaluation of inductance in a permanent magnet synchronous motor," in 2011 IEEE International Electric Machines Drives Conference (IEMDC), May 2011, pp. 1171-1176.

[21] J.-Y. Lee, S.-H. Lee, G.-H. Lee, J.-P. Hong, and J. Hur, "Determination of parameters considering magnetic nonlinearity in an interior permanent magnet synchronous motor," IEEE Transactions on Magnetics, vol. 42, no. 4, pp. 1303-1306, April 2006.

[22] A. Kilthau and J. M. Pacas, "Appropriate models for the control of the synchronous reluctance machine," in Conference Record of the 2002 IEEE Industry Applications Conference. 37th IAS Annual Meeting (Cat. No.02CH37344), vol. 4, Oct 2002, pp. 2289-2295 vol.4.

[23] T. W. Nehl, F. A. Fouad, N. A. Demerdash, and E. A. Maslowski, "Dynamic simulation of radially oriented permanent magnet-type elec- tronically operated synchronous machines with parameters obtained from finite element field solutions," IEEE Transactions on Industry Applications, vol. IA-18, no. 2, pp. 172-182, March 1982.

[24] T. W. Nehl, F. A. Fouad, and N. A. Demerdash, "Determination of saturated values of rotating machinery incremental and apparent inductances by an energy perturbation method," IEEE Transactions on Power Apparatus and Systems, vol. PAS-101, no. 12, pp. 4441-4451, Dec 1982.

[25] A. Stirban, L. Tutelea, D. Iles-Klumpner, and I. Boldea, "Fem analysis of concentrated coils nonuniform slot $(6+6 / 8)$ ipmsm fed with trapezoidal current," in 2008 11th International Conference on Optimization of Electrical and Electronic Equipment, May 2008, pp. 45-53.

[26] D. A. Staton, R. P. Deodhar, W. L. Soong, and T. J. E. Miller, "Torque prediction using the flux-mmf diagram in ac, dc, and reluctance motors," IEEE Transactions on Industry Applications, vol. 32, no. 1, pp. 180-188, Jan 1996.

[27] A. G. Jack and B. C. M. amd A. J. Mitcham, "Design and initial test results from a permanent magnet synchronous motor for a vehicle drive," in Proceedings of ICEM, vol. 2, 1992, pp. 751-755.

[28] S. D. Umans, "Total-flux representation of synchronous machines," IEEE Journal of Emerging and Selected Topics in Power Electronics, vol. 2, no. 2, pp. 341-347, June 2014.

[29] I. Boldea, Synchronous Generators (Electric Generators Handbook). CRC Press, 2015

[30] D. M. Ionel, J. F. Eastham, E. Demeter, M. J. Balchin, D. Stoia, and C. Apetrei, "Different rotor configurations for bldc motors operating in flux weakening mode," in International Conference on Electrical Machines (ICEM), 1996.

[31] G. Feng, C. Lai, and N. C. Kar, "A novel current injection-based online parameter estimation method for pmsms considering magnetic saturation," IEEE Transactions on Magnetics, vol. 52, no. 7, pp. 1-4, July 2016.

[32] S. Bolognani, S. Calligaro, R. Petrella, and M. Tursini, "Sensorless control of ipm motors in the low-speed range and at stand-still by hf-injection and dft processing," in 2009 IEEE International Electric Machines and Drives Conference, May 2009, pp. 1557-1564.

[33] A. Tessarolo, C. Bassi, and D. Giulivo, "Time-stepping finite-element analysis of a 14-mva salient-pole shipboard alternator for different damper winding design solutions," IEEE Transactions on Industrial Electronics, vol. 59, no. 6, pp. 2524-2535, June 2012

[34] A. B. Dehkordi, A. M. Gole, and T. L. Maguire, "Permanent magnet synchronous machine model for real-time simulation," in International Conference on Power Systems Transients, no. IPST05-159, June 2005.

[35] S. A. Odhano, R. Bojoi, E. Armando, G. Homrich, A. F. F. Filho, M. Popescu, and D. G. Dorrell, "Identification of three-phase IPM machine parameters using torque tests," IEEE Transactions on Industry Applications, vol. 53, no. 3, pp. 1883-1891, May 2017.

[36] S. A. Odhano, P. Pescetto, H. A. A. Awan, M. Hinkkanen, G. Pellegrino, and R. Bojoi, "Parameter identification and self-commissioning in ac motor drives: a technology status review," IEEE Transactions on Power Electronics, pp. 1-1, 2018.

[37] M. Kazerooni and N. C. Kar, "Methods for determining the parameters and characteristics of PMSM," in 2011 IEEE International Electric Machines Drives Conference (IEMDC), May 2011, pp. 955-960.

[38] R. Dutta and M. F. Rahman, "A comparative analysis of two test methods of measuring $\mathrm{d}$ - and q -axes inductances of interior permanent-magnet machine," IEEE Transactions on Magnetics, vol. 42, no. 11, pp. 37123718, Nov 2006.

[39] A. Gebregergis, M. Islam, T. Sebastian, and R. Ramakrishnan, "Evaluation of inductance in a permanent magnet synchronous motor," in 2011 IEEE International Electric Machines Drives Conference (IEMDC), May 2011, pp. 1171-1176.

[40] V. Rallabandi, N. Taran, D. M. Ionel, and P. Zhou, "Inductance testing according to the new IEEE Std. 1812-application and possible extensions for IPM machines," in 2017 IEEE Energy Conversion Congress and Exposition (ECCE), Oct 2017, pp. 4302-4308.

[41] N. Bianchi and S. Bolognani, "Magnetic models of saturated interior permanent magnet motors based on finite element analysis," in Conference Record of 1998 IEEE Industry Applications Conference. ThirtyThird IAS Annual Meeting (Cat. No.98CH36242), vol. 1, Oct 1998, pp. 27-34.

[42] T. Lange, M. Boesing, and R. W. D. Doncker, "Measurementparameterized synchronous machine model with spatial-harmonics," in 2014 17th International Conference on Electrical Machines and Systems (ICEMS), Oct 2014, pp. 3289-3295. 
[43] D. M. Ionel, M. J. Balchin, J. F. Eastham, and E. Demeter, "Finite element analysis of brushless dc motors for flux weakening operation," IEEE Transactions on Magnetics, vol. 32, no. 5, pp. 5040-5042, Sep 1996.

[44] G. Qi, J. T. Chen, Z. Q. Zhu, D. Howe, L. B. Zhou, and C. L. Gu, "Influence of skew and cross-coupling on flux-weakening performance of permanent-magnet brushless AC machines," IEEE Transactions on Magnetics, vol. 45, no. 5, pp. 2110-2117, May 2009.

[45] A. Chiba, F. Nakamura, T. Fukao, and M. A. Rahman, "Inductances of cageless reluctance-synchronous machines having nonsinusoidal space distributions," IEEE Transactions on Industry Applications, vol. 27, no. 1, pp. 44-51, Jan 1991.

[46] R. Dutta, M. F. Rahman, and L. Chong, "Winding inductances of an interior permanent magnet (ipm) machine with fractional slot concentrated winding," IEEE Transactions on Magnetics, vol. 48, no. 12, pp. 4842-4849, Dec 2012.

[47] S. A. Odhano, R. Bojoi, E. Armando, G. Homrich, A. F. F. Filho, M. Popescu, and D. G. Dorrell, "Parameter extraction for three phase IPM machines through simple torque tests," in 2015 IEEE Energy Conversion Congress and Exposition (ECCE), Sept 2015, pp. 18921898.

[48] P. H. Mellor, F. B. Chaaban, and K. J. Binns, "Estimation of parameters and performance of rare-earth permanent-magnet motors avoiding measurement of load angle," IEE Proceedings B - Electric Power Applications, vol. 138, no. 6, pp. 322-330, Nov 1991. 